Article

\title{
Electrokinetic Characterization of Natural Stones Coated with Nanocomposites for the Protection of Cultural Heritage
}

\author{
Marco Roveri ${ }^{1, *}$, Simona Raneri ${ }^{2}$, Sabrina Bianchi ${ }^{3}$, Francesca Gherardi ${ }^{4}(\mathbb{0}$, \\ Valter Castelvetro $^{3,5, *(1)}$ and Lucia Toniolo ${ }^{1,3}$ \\ 1 Dipartimento di Chimica, Materiali e Ingegneria Chimica “Giulio Natta”, Politecnico di Milano, \\ Piazza Leonardo da Vinci, 32, 20133 Milan, Italy; lucia.toniolo@polimi.it \\ 2 Dipartimento di Scienze della Terra, Università di Pisa, Via Santa Maria, 53, 56126 Pisa, Italy; \\ simona.raneri@unipi.it \\ 3 National Interuniversity Consortium of Materials Science and Technology (INSTM), via G. Giusti, 9, \\ 50121 Firenze, Italy; sabrinab@dcci.unipi.it \\ 4 School of Chemistry, University of Lincoln, Lincoln LN6 7TS, UK; fra.gherardi@gmail.com \\ 5 Dipartimento di Chimica e Chimica Industriale, Università di Pisa, Via G. Moruzzi, 13, 56124 Pisa, Italy \\ * Correspondence: marco.roveri@polimi.it (M.R.); valter.castelvetro@unipi.it (V.C.); \\ Tel.: +39-320-711-1008 (V.C.)
}

Received: 31 August 2018; Accepted: 17 September 2018; Published: 19 September 2018

check for updates

Featured Application: Characterization of the quality and homogeneity of surface treatments for porous substrates.

\begin{abstract}
Protective coatings, in recent years also from nanocomposite formulations, are commonly applied onto architectural stone and stone artefacts, mainly to prevent absorption of condensed water and dissolved atmospheric pollutants into the porous stone structure. While standard protocols to assess a coating's performance are available, understanding the response of the coating-stone system is a complex task, due to the interplay of various factors determining the overall behaviour. Characterization techniques allowing one to correlate the extent and nature of surface modification upon treatment with the most relevant physical properties (i.e., water absorption and surface wettability) are thus of great interest. Electrokinetic analysis based on streaming current measurements, thanks to its sensitivity towards even minor changes in the surface chemical composition, may fulfil such requirement. Indeed, by involving the interaction with a testing aqueous electrolyte solution, this technique allows one to probe not only the outer surface, but also the outermost layer of the pore network, which plays a crucial role in the interaction of the stone with condensed atmospheric water. In this work, a correlation was found between the extent of surface modification, as determined by streaming current measurements, surface wettability and capillary water absorption, for three lithotypes with different mineralogical and microstructural properties treated with two nanocomposite formulations (one water based and one in alcoholic solvent) containing organosilica precursors and titania nanoparticles.
\end{abstract}

Keywords: natural stones; alkylalkoxysilane; nanocomposite coatings; surface modification; zeta potential; streaming current

\section{Introduction}

The protection of natural stones used in historical architecture is generally carried out through the application of suitable water-repellent coatings, which prevent the capillary absorption of condensed 
water and dissolved atmospheric pollutants into the porous stone network, thereby limiting the associated deterioration phenomena [1]. Since the effectiveness of these coatings mostly relies on their ability to modify the interaction of the treated surface with water, understanding the extent of surface modification, both in terms of effective surface coverage and change of chemical properties, is a key issue for the prediction of protective efficacy [2].

The effects of a hydrophobic coating on the surface properties can be studied at the macroscopic level by evaluating the behaviour of the treated stone with respect to established physical parameters, among which capillary water absorption and surface wettability have the highest relevance. Complementary to this, electron and atomic force microscopy give an insight into treatment-induced changes of the stone surface morphology at the micro- and nano-scale [3,4], while SEM-EDX (Scanning Electron Microscopy with Energy-dispersive X-ray probe) and FTIR spectroscopies may allow one to detect the presence and the surface distribution of a coating material through the observation of atomic [5] and molecular spectra [6], respectively.

However, linking information at the microscale, e.g., from observation of stone surface morphology, to macroscopic effects in terms of physical behaviour can be especially arduous. In the first place, natural stones are heterogeneous systems with high complexity and variety in terms of microstructure and mineralogical composition. Secondly, the wide range of coating materials that may be used in stone protection show markedly different properties, as well. Thus, the main factors responsible for the overall behaviour of the system towards water may be very difficult to identify, all of which makes a prediction of the effectiveness of a coating material an arduous or impossible task [7]. Besides that, for porous solids such as natural stones, the very concept of "surface" defies a clear-cut definition; in fact, the effective surface area interacting with external agents and/or with a protective coating material upon its application includes both the macroscopic outer surface and the outermost part of the pore network, insofar as the pore walls may also be involved in such interaction. Thus, upon application of a water repellent treatment, its contribution to the modification of surface topography and properties depends on the product penetration, reactivity and distribution. Unfortunately, surface analysis of stones, e.g., by electron microscopy techniques to explore the outer surface or even polished cross-sectional ones, does not allow a 3D description of the stone surface morphology and of the pore network topography sufficiently complete and representative of the inner microstructure [8]. In particular, only limited information about the actual amount and distribution of the treating material can be attained in this way. This is a significant limitation, since the interaction of the stone with condensed water is determined not only by the outermost surface, but also by the pore walls and shape near the very surface. As further shortcomings, the spectroscopic detection of silicon-based products, which are currently the class of materials most widely employed for natural stone treatment [9], is generally difficult on stones containing quartz or clay minerals, while the detection of the presence and homogenous distribution of a coating layer based on morphology can be critical on any stone if the applied product generates nanometric layers resulting in barely visible modifications of the stone surface [10].

In view of better understanding the extent of surface modification of stones after the application of a protective product or formulation, a potentially useful contribution may come from electrokinetic analysis based on streaming potential/streaming current measurements. As far as macroscopic and non-conductive solid materials are concerned, these measurements have established themselves as valuable tools for investigating the chemical properties of solid/liquid interfaces [11] and, in particular, for pinpointing the contribution of the surface chemical composition to the electrostatic component of the overall interaction with an electrolyte-carrying aqueous medium. Moreover, it must be considered that, in the case of a porous substrate, an aqueous medium is also likely to interact with the outermost layer of the pore network, and since the latter may be significantly modified upon application of a protective treatment, electrokinetic analysis may allow a more complete and far-reaching characterization of treatment-induced changes of surface properties. 
The theoretical foundations of electrokinetic techniques were laid more than one century ago by von Smoluchowski [12], who introduced the fundamental concept of zeta potential and described its measurement by drawing on Helmholtz's theory of the electrical double layer (EDL). Zeta potential is defined as the electric potential at the slip plane of a solid/electrolyte interface, the slip plane being a virtual surface separating the layer of molecules and ions immobilized by adsorption onto the solid surface (roughly the Stern layer) from the rest of the EDL where they are free to move. Its magnitude reflects the net charge density at the solid surface and the charge distribution in the EDL and is an indicator of the ability of the solid material to establish electrostatic interactions with charged species (ions of the electrolyte, colloidal particles) coming close to its surface. In a streaming current or a streaming potential measurement, a macroscopic laminar flow of the electrolyte fluid tangential to the solid surface is induced by a hydrostatic pressure gradient, resulting in a net charge flow if the EDL presents an unbalanced ionic composition, as is the case when the zeta potential is not zero. This convective transport of mobile ions in the direction of the liquid flow, which is called streaming current, can be detected directly by measuring the electric current between two non-polarizable electrodes positioned up- and down-stream, respectively, with an electrometer of sufficiently low internal resistance. Alternatively, the electric potential generated by the convective charge transport, or streaming potential, can be measured between the same two electrodes with a high-input impedance voltmeter. According to the Smoluchowski model, if the EDL is sufficiently thin and the flow is laminar, the zeta potential is directly proportional to the derivative of streaming current $\left(\mathrm{I}_{\mathrm{s}}\right)$ with respect to the applied pressure difference $(\Delta \mathrm{p})$, according to Equation (1):

$$
\zeta=\frac{\mathrm{dI}}{\mathrm{d} \Delta \mathrm{p}} \cdot \frac{\eta \cdot \mathrm{k}}{\varepsilon_{0} \cdot \varepsilon} \cdot \mathrm{R}
$$

where $\kappa, \varepsilon$ and $\eta$ are the electrical conductivity, dielectric constant and viscosity of the bulk electrolyte solution, respectively, $\varepsilon_{0}$ is the vacuum permittivity and $\mathrm{R}$ is the electrical resistance of the streaming channel.

Currently, the electrokinetic characterization via streaming current/streaming potential measurements is the most straightforward technique for measuring the zeta potential of macroscopic solid surfaces, and it has been used for a broad range of materials, including paper, textiles, membranes, biomaterials, soil and minerals [13-19]. Electrokinetic measurements provide a mean for studying such different phenomena as the adsorption of ionic species on inorganic substrates or of proteins on surfaces of biological interest, as well as the extent of modification of the substrate surface and its time-dependent evolution [20]. Furthermore, the zeta potential can be an extremely useful parameter in the description of granular or fibrous materials and of porous ones such as, e.g., semipermeable membranes [21] and natural stones [22], especially in connection with their behaviour in aqueous media as a function of $\mathrm{pH}[23,24]$. Nevertheless, there is still a nearly complete lack of studies concerning the characterization of natural stone surfaces [25] and the effect on the surface zeta potential resulting from treatment applications [26].

The aim of the present study is to explore the potential of electrokinetic analysis as a tool to better understand the changes occurring at the surface of natural stones after the application of protective coatings. For this purpose, the results of streaming current measurements are compared with the observed changes in the stone-water interaction as assessed by two commonly employed parameters for the evaluation of protective effectiveness, namely surface wettability and water absorption by capillarity [9]. It is worth stressing that a multiplicity of factors contributes to the effectiveness of a protective coating, particularly if nanocomposite is in its formulation; among them, the porosity, pore size distribution and roughness of the substrate; the intrinsic hydrophobicity of the coating material and its ability to produce a uniform and continuous (but not occluding) layer sheeting both the outer stone surface and the outermost pore walls.

The present study was focused on devising an electrokinetic-based parameter suited for the semi-quantitative estimation of the degree of surface modification, allowing a prediction of the overall 
behaviour of a given coating-stone system. For this purpose, three lithotypes (natural stones selected among those used as construction materials in historic buildings) with different microstructural and mineralogical properties and two different coating formulations were considered. The formulations, consisting of liquid dispersions of different organosilica matrix precursors combined with titania nanoparticles, were developed in the framework of the EU-funded NanoCathedral project, dealing with the setup and testing of innovative nanocomposite materials for the conservation of European architectural heritage. Their protective effectiveness was evaluated by static contact angle and water absorption measurements, performed on the lithotypes before and after the application of the coating formulations. In addition, electrokinetic characterization of untreated and treated stones and of the coatings obtained by casting onto a non-porous reference substrate was performed. The existence of well-defined correlations between the changes induced by the coatings on the electrokinetic properties and the reduction of surface wettability and of capillary water absorption in the treated stones was investigated.

\section{Materials and Methods}

\subsection{Lithotypes}

Three different types of unweathered stones $(5 \times 5 \times 2 \mathrm{~cm}$ specimens) freshly cut from quarried blocks were used: Apuan marble, Balegem limestone and Obernkirchen sandstone (Figure 1). Apuan marble (Carrara, Italy), a metamorphic rock with very low porosity, is almost pure calcite; Balegem stone is a compact limestone from the Ghent region (Belgium), exhibiting many millimetre-sized cavities; it is composed of siliceous clasts in a sparitic calcite and dolomite cement; Obernkirchen stone is a fine-grained porous sandstone (Obernkirchen, Lower Saxony, Germany), and its composition includes mainly quartz with some kaolinite, feldspars and dolomite [27]. These natural stones have particular relevance in the cultural heritage field: Apuan marble is universally known for its centuries-long use in the fields of sculpture and architecture; Balegem stone was widely employed as a building material in the Flanders region and is found in monuments such as St. Bavo's Cathedral in Ghent (XIII-XVI Century); Obernkirchen stone is especially renowned for being one of the lithotypes used in the construction of Cologne Cathedral (XIII-XIX Century).
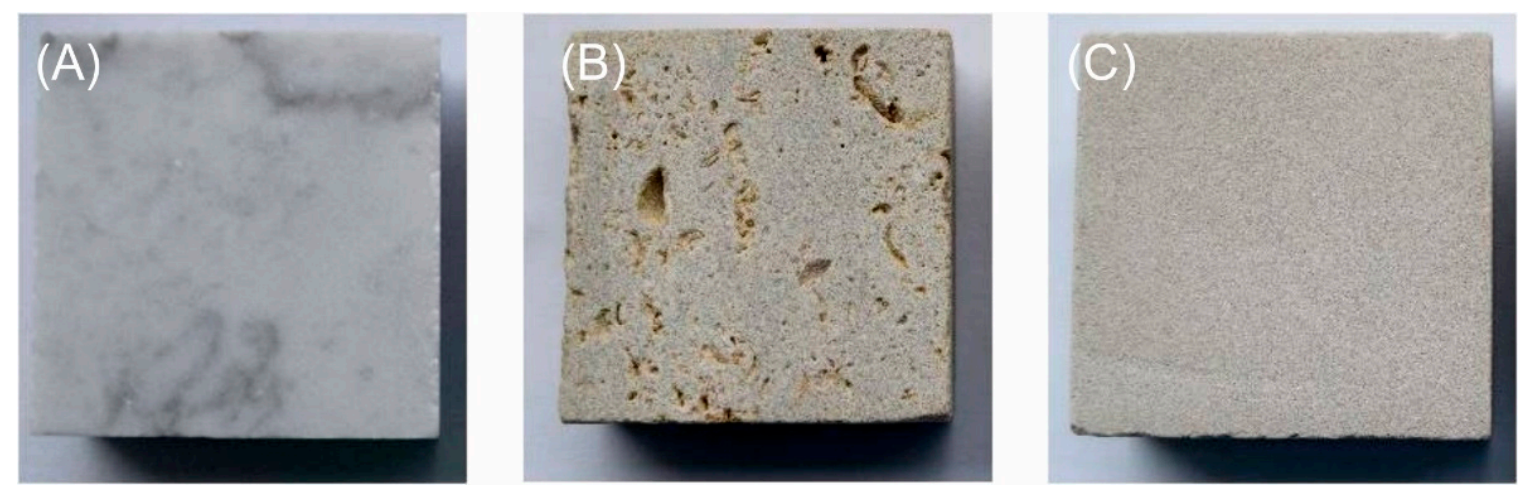

Figure 1. Photographs of Apuan marble (A) Balegem limestone (B) and Obernkirchen sandstone (C) prism specimens $(5 \times 5 \times 2 \mathrm{~cm})$.

In order to investigate the microstructure of lithotypes, Mercury Intrusion Porosimetry (MIP) measurements in the $0.01-100 \mu \mathrm{m}$ range were performed in two replicates per lithotype on 1- $\mathrm{cm}^{3}$ stone specimens according to the standard procedure [28] to collect total open porosity and average pore diameter data.

Surface roughness was analysed by Atomic Force Microscopy (AFM) using a Solver Pro AFM microscope (NT-MDT Spectrum Instruments) equipped with a silicon cantilever bearing a tip of 14-16 $\mu \mathrm{m}$ in height (NSG10, NT-MDT) with a tip curvature radius of $10 \mathrm{~nm}$ at a resonant frequency of 
140-390 KHz. Measurements were performed in tapping mode at a 0.6-Hz scan rate, with 2 scans of a $0.5 \times 0.5-\mu \mathrm{m}$ area. The acquired images were elaborated through the Nova SPM software (NT-MDT Spectrum Instruments, Moscow, Russia).

The total open porosity, average pore diameter and Root Mean Square (RMS) values of surface roughness of the three lithotypes are reported in Table 1.

Table 1. Open porosity, average pore diameter and surface roughness (Root Mean Square (RMS)) of the three lithotypes.

\begin{tabular}{cccc}
\hline Stone Type & $\begin{array}{c}\text { Open Porosity } \\
(\mathbf{v o l} \%)\end{array}$ & $\begin{array}{c}\text { Average Pore Diameter } \\
(\boldsymbol{\mu m})\end{array}$ & $\begin{array}{c}\text { RMS Roughness } \\
(\mathbf{n m})\end{array}$ \\
\hline Apuan Marble & $0.7 \mathrm{a}$ & $0.08 \mathrm{a}$ & $6^{1}$ \\
Balegem & $9.9 \pm 0.8$ & $0.28 \pm 0.06$ & $38 \pm 8$ \\
Obernkirchen & $24.1 \pm 0.1$ & $0.8 \pm 0.3$ & $10 \pm 9$ \\
\hline
\end{tabular}

${ }^{1}$ In the case of Apuan marble, measurements were only carried out on one specimen.

\subsection{Nanocomposite Products}

The two nanocomposite formulations used in this study, hereafter referred to as WNC (water-based nanocomposite) and ANC (alcohol-based nanocomposite), were developed by companies (ChemSpec srl, Peschiera Borromeo, Italy; Colorobbia Consulting srl, Sovigliana, Italy) in the framework of the EU-funded NanoCathedral project [27]. They consist of $\mathrm{TiO}_{2}$ nanoparticles dispersed in alkylalkoxysilane reactive sols. The details of their preparation are protected by a non-disclosure agreement, and only partial information on their components was supplied by the producers (Table 2).

In order to characterize the rheological behaviour of the products, a CV0 120 Rheometer (Bohlin Instruments Vertrieb GmbH, now Malvern Panalytical Ltd., Malvern WR14 1XZ, UK) was employed, using a cone-plate configuration ( $1^{\circ}$ angle, $40-\mathrm{mm}$ diameter) with a $0.03-\mathrm{mm}$ gap. The measurements were conducted for $3 \mathrm{~min}$ under $0.01-3 \mathrm{~Pa}$ stress at $20^{\circ} \mathrm{C}$. Since the products exhibited a shear-thinning behaviour, the value of viscosity measured in the low shear rate region around $4 \mathrm{~s}^{-1}$ (Table 2) was assumed to be representative of the rheological behaviour of the products in a capillary flow regime.

Particle size was measured on a 90 Plus Dynamic Laser Light Scattering instrument (Brookhaven Instruments Corporation, Holtsville, NY, USA) equipped with a 35-mW laser and an Avalanche photodiode detector collecting the scattered light at $90^{\circ}$.

Table 2. Main chemical properties of the two nanocomposites.

\begin{tabular}{|c|c|c|}
\hline Main Features of Formulation & WNC (Water-Based Nanocomposite) & ANC (Alcohol-Based Nanocomposite) \\
\hline Solvent & water & 2-propanol \\
\hline Main component ${ }^{1}$ & aminoalkyl-trialkoxysilane (oligomers) & monomeric alkylalkoxysilane \\
\hline Concentration $(w t / w t)^{1}$ & $15 \%$ & $40 \%$ \\
\hline Density $\left(\mathrm{g} / \mathrm{cm}^{3}\right)$ & 1.03 & 0.84 \\
\hline Viscosity (mPa $\cdot \mathrm{s})$ & 12 & 6 \\
\hline $\mathrm{pH}$ & 4.5 & n.a. \\
\hline $\mathrm{TiO}_{2}(\mathrm{ppm})^{1}$ & 9600 & 1200 \\
\hline $\mathrm{TiO}_{2}$ particle size $(\mathrm{nm})$ & 106 & 25 \\
\hline
\end{tabular}

${ }^{1}$ Data supplied by the producers.

The protective effectiveness and the general properties of these products have already been assessed in previous studies $[29,30]$. The alkyl groups provide the coatings with hydrophobic properties, while $\mathrm{TiO}_{2}$ nanoparticles at low concentration are introduced to impart photocatalytic and self-cleaning properties. Upon solvent evaporation, the sol-gel condensation turns the alkylalkoxysilane precursors into cross-linked organosilica networks, their adhesion onto stone substrates being the result of both noncovalent (hydrogen bonding and dipolar interactions of the mineral surface with unreacted silanol 
groups, with additional ionic interactions involving protonated amine in WNC) and covalent (sol-gel condensation with surface silanols of silicate stones) interactions.

\subsection{Treatment Procedure}

The stone specimens $(5 \times 5 \times 2 \mathrm{~cm}$ prisms; Figure 1$)$ were gently ground with abrasive paper (P180 carborundum paper), kept in deionized water for an hour in order to remove any excess of soluble salts, dried in an oven at $50{ }^{\circ} \mathrm{C}$ until constant weight (a minimum of $48 \mathrm{~h}$ ) and finally stored in a silica gel desiccator at room temperature for another $24 \mathrm{~h}$. Three specimens were prepared for each lithotype and treatment combination. The nanocomposites were applied by capillary absorption using a filter paper pad saturated with the treating material, according to the EN 16581:2014 protocol [31], for $6 \mathrm{~h}$. After treatment application, the specimens were kept sheltered from light for 1 month at the temperature and humidity conditions of the lab (about $25^{\circ} \mathrm{C}$ and $50 \%$ r.h.) and finally placed again in the silica gel desiccator for $24 \mathrm{~h}$ before being weighed. In order to determine the amount of dry matter applied, all specimens were weighed (ATILON ATL-224-I, Acculab, a brand from Sartorius $\mathrm{GmbH}$, Goettingen, Germany) before the treatment and then after 1 month, which was considered as a sufficient time for a nearly quantitative sol-gel reaction to occur. It is worth mentioning that in the case of sol-gel reactions, further weight loss follows solvent evaporation, as a result of the loss of alcohol molecules upon alkoxysilane hydrolysis (e.g., ethanol from ethoxysilane groups) and loss of water molecules upon siloxane bond formation, so achieving truly constant weight is a matter of approximation. The amounts of dry matter absorbed per unit area, as determined 1 month after the application, are reported in Table 3.

Table 3. Dry matter per unit area $\left(\mathrm{mg} / \mathrm{cm}^{2}\right)$ absorbed by the stone specimens treated with WNC and with ANC (each value is the average from three treated specimens).

\begin{tabular}{ccc}
\hline Stone Type & WNC & ANC \\
\hline Apuan marble & $<0.01$ & $0.5 \pm 0.2$ \\
Balegem & $6 \pm 3$ & $10 \pm 2$ \\
Obernkirchen & $7 \pm 1$ & $20 \pm 4$ \\
\hline
\end{tabular}

Each product was also cast at room temperature on glass slides $(25 \times 75 \mathrm{~mm})$ that had been previously treated with hot Piranha solution $\left(95 \% \mathrm{H}_{2} \mathrm{SO}_{4}\right.$ and $30 \% \mathrm{H}_{2} \mathrm{O}_{2}$ in 3:1 volume ratio) for $15 \mathrm{~min}$ to increase the amount of reactive silanol groups on the glass surface. The slides were kept under saturated solvent atmosphere until complete evaporation of the solvent (water/2-propanol) and formation of a thin film, then stored under the same conditions until the electrokinetic measurement was performed.

\subsection{Testing of Stone Specimens}

\subsubsection{Streaming Current Measurements}

Streaming current measurements on untreated/treated lithotypes and glass slides were performed using the SURPASS Electrokinetic analyser (Anton Paar $\mathrm{GmbH}$, Graz, Austria), with a measuring cell covering an area of $25 \times 5 \mathrm{~mm}$. Then, $10^{-3} \mathrm{M} \mathrm{KCl}$ in ultrapure water $(18.2 \mathrm{M} \Omega \cdot \mathrm{cm})$ was used as the electrolyte. In each measurement, four pressure ramps from 0-400 mbar were applied, and the apparent zeta $(\zeta)$ potential was calculated from the slope of streaming current vs. pressure, according to the Smoluchowski Equation (1). Here, the apparent $\zeta$ potential was considered since in tangential electrokinetic measurements performed on a porous substrate, the ionic conductivity within the porous structure and in the stagnant layer (shallows of the outer rough surface lying below the slip plane) contributes to the observed streaming current. While this contribution is difficult to evaluate by streaming potential measurements, it can be accounted for by performing streaming current measurements at different heights of the gap between the measuring cell surfaces [32]. 
Unfortunately, the adjustable gap cell required for such a measurement is not suited for the analysis of large specimens such as the natural stone samples of the present study. Nevertheless, the apparent $\zeta$ potential considered hereafter, though not accurate for describing the average surface charge density of such samples, is still a useful parameter to evaluate the extent of modifications induced by the application of a treatment modifying both the outer stone surface and, to some extent, the pore walls. The isoelectric point (IEP), i.e., the $\mathrm{pH}$ value at which $\zeta=0$, was determined by performing a sequence of measurements at slightly different $\mathrm{pH}$ values by means of an automatic titrator. Treated lithotypes and glass slides were analysed 1 month after the application of the products in order to allow for the formation of a seemingly stable gel network.

The shift of the isoelectric point relative to the untreated lithotype ( $\triangle \mathrm{IEP})$ is given in Equation (2):

$$
\Delta \mathrm{IEP}=\frac{\mathrm{IEP}_{\mathrm{t}}-\mathrm{IEP}_{\mathrm{nt}}}{\mathrm{IEP}_{\mathrm{nt}}}
$$

where IEP $P_{t}$ is the isoelectric point of the treated lithotype and IEP $n$ that of the untreated lithotype.

Then, in order to explore the possibility of using electrokinetic data for a quantitative estimation of the extent of surface modification produced by the two coatings, the shift of the isoelectric point was normalized according to Equation (3):

$$
\mathrm{ISM}=\frac{\left|\mathrm{IEP}_{\mathrm{t}}-\mathrm{IEP} \mathrm{Pt}_{\mathrm{nt}}\right|}{\left|\mathrm{IEP}_{\mathrm{s}}-\mathrm{IEP}_{\mathrm{nt}}\right|}
$$

where ISM stands for index of surface modification, an empirical parameter proposed here as a means for evaluating the change in surface properties with respect to the untreated lithotype, and IEP $\mathrm{S}_{\mathrm{S}}$ is the isoelectric point of the coating applied on glass slides.

\subsubsection{Water Absorption Measurements}

Capillary water absorption was measured up to $96 \mathrm{~h}$ following the EN Standard Protocol $[33,34]$. The relative capillary index as defined in Equation (4):

$$
\mathrm{IC}_{\mathrm{rel}}=\text { integral }_{\mathrm{t}} / \text { integral }_{\mathrm{nt}}
$$

that is, the ratio of the absorption integrals of treated and untreated specimens, was used to compare the water absorption behaviour of treated and untreated stones.

\subsubsection{Static Contact Angle Measurements}

Static contact angle $(\theta)$ measurements were performed on 15 areas for each specimen, according to the EN Standard Protocol [35], using an OCA 20 PLUS optical contact angle instrument (DataPhysics Instruments $\mathrm{GmbH}$, Filderstadt, Germany), with a drop volume of $5 \mu \mathrm{L}, 10$ seconds after drop deposition. The test was carried out before and after the application of the treatments. The increase in contact angle from untreated to treated specimens $\left(\Delta \theta=\theta_{t}-\theta_{n t}\right)$ was assumed as the parameter representing the reduction of surface wettability.

\section{Results and Discussion}

\subsection{Electrokinetic Analysis of Untreated Lithotypes}

Streaming current measurements were performed on the three untreated lithotypes at various $\mathrm{pH}$ within different ranges, depending on the chemical stability of each given stone, to obtain their respective isoelectric points (IEP, Table 4); for this purpose, titration curves were drawn by fitting the zeta potential values calculated from the streaming current data (Figure 2). Even though the electrokinetic behaviour of porous materials is the result of a variety of factors, including the influence of surface conductance [32] and the effect of surface roughness [36], the differences observed among 
IEPs can be seen to reflect the mineralogical composition of the lithotypes under study quite closely. This indicates that the isoelectric point may be a suitable parameter for characterizing stones with different surface chemical composition, and in particular for distinguishing among those with different contributions of carbonate and silicate minerals. In particular, the isoelectric point of Obernkirchen, i.e., a stone largely consisting of quartz, is in good agreement with the values reported in the literature for silica and layered silicates [37,38]. In the case of Apuan marble, which is almost pure calcite, a comparison with literature data concerning calcite samples showed only partial agreement [39]; however, upon performing the electrokinetic titration on a single crystal of calcite, an IEP value in close correspondence to that determined on the marble was obtained.

Table 4. Mineralogical composition (calcite + dolomite content, in mol\%), values of $\zeta$ potential at $\mathrm{pH} 7$ and 5 (in $\mathrm{mV}$ ) and isoelectric points (IEP, in $\mathrm{pH}$ units) of untreated lithotypes.

\begin{tabular}{|c|c|c|c|c|}
\hline Stone Type & $\begin{array}{c}\text { Calcite + Dolomite } \\
(\mathrm{mol} \%)\end{array}$ & $\begin{array}{c}\zeta(\mathrm{pH} \mathrm{7)} \\
(\mathrm{mV})\end{array}$ & $\underset{(\mathrm{mV})}{\zeta(\mathrm{pH} 5)}$ & $\begin{array}{c}\text { IEP } \\
\text { (pH Units) }\end{array}$ \\
\hline Apuan marble & 99.6 & $-60 \pm 4$ & $-47 \pm 4$ & $3.7 \pm 0.1$ \\
\hline Balegem & 53.1 & $-57 \pm 6$ & $-48 \pm 8$ & $3.0 \pm 0.3$ \\
\hline Obernkirchen & 1.2 & $-88 \pm 10$ & $-73 \pm 5$ & $2.1 \pm 0.2$ \\
\hline Calcite monocrystal & 100 & - & -39 & 3.6 \\
\hline
\end{tabular}

${ }^{1}$ from X-ray diffraction measurements [27].

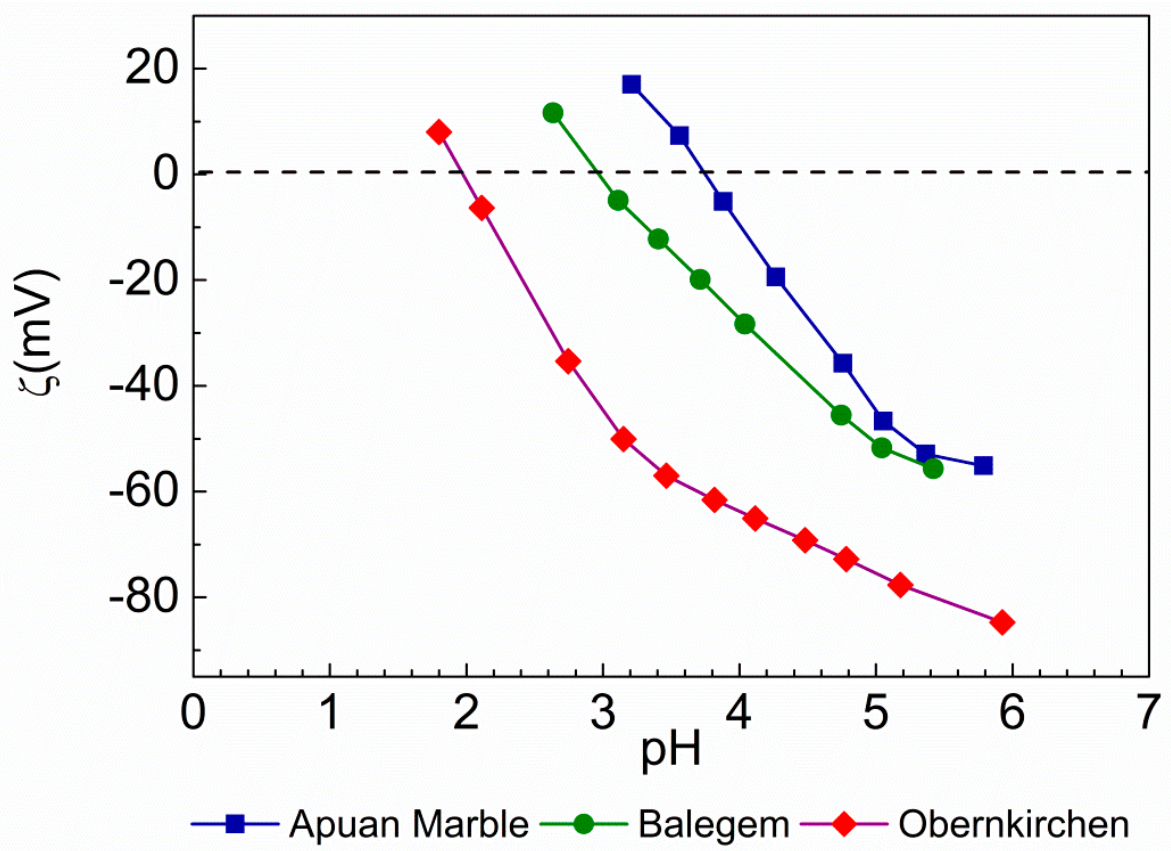

Figure 2. Example of titration curves expressing $\zeta$ potential as a function of $\mathrm{pH}$ for the three lithotypes: Apuan marble, Balegem limestone and Obernkirchen sandstone.

\subsection{Electrokinetic Analysis of Nanocomposites}

From the results of the streaming current measurements on the two nanocomposite coatings applied onto glass slides (Table 5), quite different IEPs were found, as expected from the different chemical structure of their components. In particular, the IEP of the WNC coating, which is based on an aminoalkyl trialkoxysilane precursor, lies in the alkaline $\mathrm{pH}$ region, in agreement with the presence of an amine group, its value being close to those reported in the literature for other materials modified with aminosilane or aminosiloxane compounds [40,41]. On the other hand, the IEP of the ANC coating, based on an alkyl trialkoxysilane precursor, while being lower than that of WNC, turned out to be quite higher than those reported elsewhere for similar compounds [42]; this mismatch may depend on 
the different surface density of slightly acidic silanol groups resulting from the alkoxysilane hydrolysis not followed by exhaustive sol-gel condensation. In an aqueous environment, silanols are in their hydrolysed form and bear a negative charge, thus contributing to reducing the $\zeta$ potential (and the IEP) of the surface. Depending on the molecular structure of the precursor and on the experimental conditions upon coating application (temperature, humidity, presence of catalytically active acidic or basic species in the formulation or at the surface of the glass substrate that was pre-treated with Piranha solution), the surface density of free silanol groups may change, and the $\zeta$ potential may be affected accordingly. In addition, the surface density of silanols may change over an extended period of time (much longer than the four weeks of ageing allowed here to stabilize the coating before performing the measurements), as the sol-gel hydrolysis and condensation reactions proceed. Finally, a possibly not negligible contribution of the $\mathrm{TiO}_{2}$ nanoparticles to the electrokinetic properties of the nanocomposite film surface should also be considered. In fact, $\mathrm{TiO}_{2}$ has an IEP of 6.2, higher than that of pure silica, with little difference between the two most common crystalline polymorphs anatase and rutile [43]. Streaming current measurements performed on coatings cast on glass slides from the respective. $\mathrm{TiO}_{2}$-free silane dispersions gave the same results as the respective fully formulated coatings containing $\mathrm{TiO}_{2}$ nanoparticles, possibly because of the low concentration of $\mathrm{TiO}_{2}$ nanoparticles and/or because they become mainly embedded in the organosilica gel network.

Table 5. Isoelectric points (IEP, in $\mathrm{pH}$ units) of the two nanocomposites applied on glass slides.

\begin{tabular}{cc}
\hline Coating & IEP (pH Units) \\
\hline WNC & $10.3 \pm 0.7$ \\
ANC & $7.9 \pm 0.8$ \\
\hline
\end{tabular}

\subsection{Electrokinetic Analysis of Treated Lithotypes}

The results of the streaming current measurements on treated lithotypes (Table 6 and Figure 3) show that a remarkable increase in IEP took place in all cases after the application of the treating products. As one may expect, the largest IEP changes were recorded for stones treated with WNC, the product providing a coating material with the highest inherent isoelectric point (Table 5). Furthermore, the differences among the IEPs of untreated lithotypes (Table 4) ended up being partially masked after application of the products. For example, Obernkirchen stone, with its lowest IEP as an untreated material, once treated showed nearly the same IEP values as the Apuan marble, a clear indication that the surface properties of the stones became dominated by those of the coating material. However, such differences were not completely cancelled out, and the IEP values of the treated stones were always lower than those measured on the coatings prepared on non-porous glass substrate. This suggests that the treating products did not succeed in producing a continuous and uniform coating layer on the mineral surface, including the pore walls of the outermost layer of the porous stone network.

Table 6. Values of $\zeta$ potential at $\mathrm{pH} 7$ (in $\mathrm{mV}$ ) and isoelectric points (in $\mathrm{pH}$ units) of lithotypes before and after treatment with WNC/ANC.

\begin{tabular}{ccccccccc}
\hline \multirow{2}{*}{ Stone Type } & \multicolumn{4}{c}{ WNC } & \multicolumn{3}{c}{ ANC } \\
\cline { 2 - 9 } & \multicolumn{2}{c}{ Untreated $^{\mathbf{1}}$} & \multicolumn{2}{c}{ Treated } & \multicolumn{2}{c}{ Untreated $^{\mathbf{1}}$} & \multicolumn{2}{c}{ Treated $^{\text {IEP }}$} \\
\cline { 2 - 9 } & $\zeta$ & \multicolumn{2}{c}{ IEP } & $\zeta$ & IEP & $\zeta$ & IEP \\
\hline Apuan marble & $-58 \pm 2$ & $3.7 \pm 0.2$ & $24 \pm 3$ & $8.4 \pm 0.6$ & $-62 \pm 3$ & $3.7 \pm 0.1$ & $7 \pm 6$ & $7.51 \pm 0.06$ \\
Balegem & $-54 \pm 5$ & $2.8 \pm 0.3$ & $9 \pm 5$ & $7.7 \pm 0.2$ & $-61 \pm 2$ & $3.1 \pm 0.1$ & $-22 \pm 10$ & $6.4 \pm 0.3$ \\
Obernkirchen & $-93^{2}$ & $2.0 \pm 0.1$ & $43^{2}$ & $8.9 \pm 0.3$ & $-85 \pm 10$ & $2.2 \pm 0.2$ & $1 \pm 1$ & $7.1 \pm 0.3$ \\
\hline
\end{tabular}

${ }^{1}$ In order to take into account the inherent variability of lithotypes, electrokinetic data were always collected on the same specimens before and after the application of the coatings; hence, two distinct sets of values are reported for untreated lithotypes. ${ }^{2}$ For WNC on Obernkirchen stone, $\zeta$ potential at $\mathrm{pH} 7$ was only measured on one specimen. 


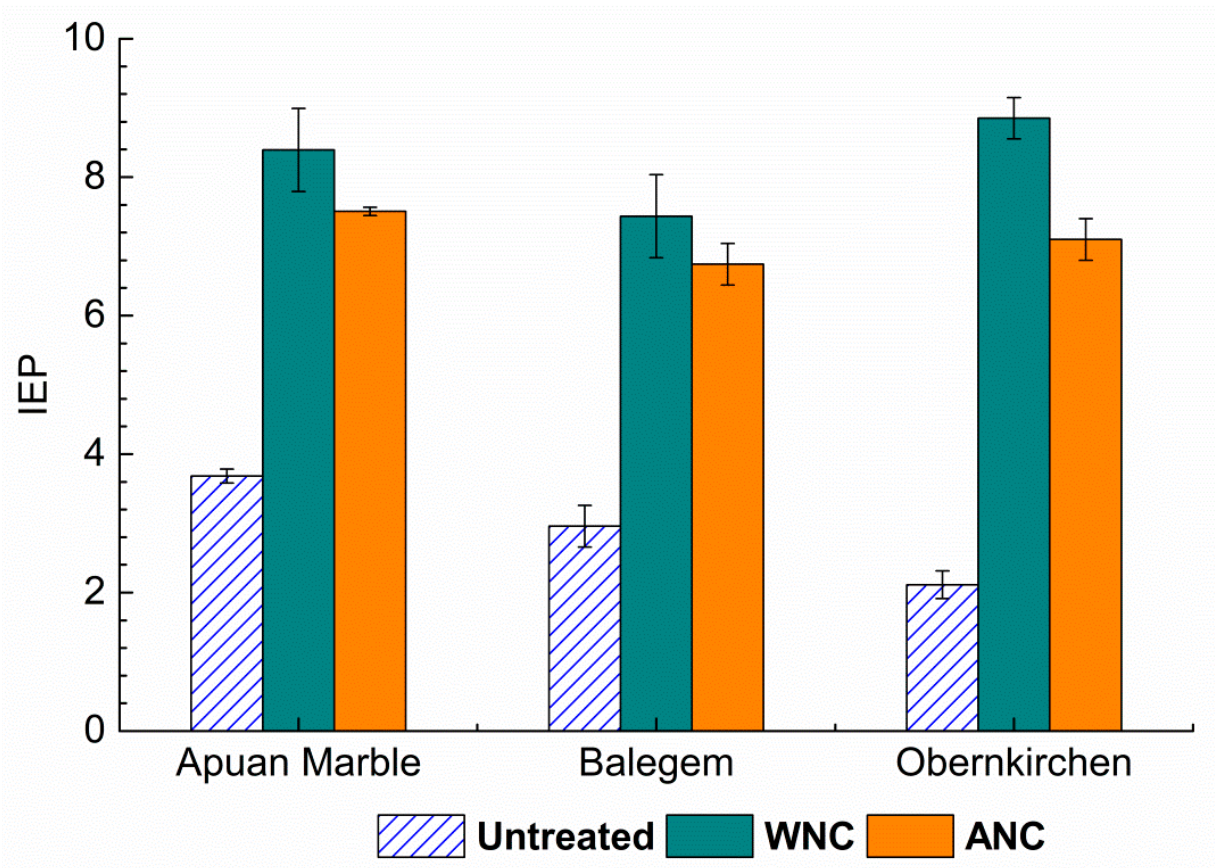

Figure 3. Isoelectric points (IEP, in $\mathrm{pH}$ units) of the three lithotypes before and after treatment with WNC/ANC. Values for untreated lithotypes were obtained by averaging the two sets of values reported in Table 6.

The extent to which the isoelectric point of stones is modified upon treatment may not linearly correlate with the actual fraction of surface coverage (SEM micrographs taken to assess the modification of surface morphology are available as Supplementary Materials, Figures S1-S3), a complex parameter of surface modification also affected by the stone porosity features being more likely [32] and, when it applies, by the occurrence of chemical reactions between the stone and the coating material. Indeed, in the case of a porous substrate, the streaming current reflects not only the charge of the EDL from the external surface, but also the contribution from pore walls sensed by the tangential electrolyte flow. Thus, the penetration depth of the treating product and its effectiveness in generating a thin coating layer on the pore walls are additional factors affecting the streaming current measurements.

In our case, the results of electrokinetic measurements clearly indicated that, while both coating formulations succeeded in producing a significant modification of the surface chemical properties of the treated stones, the surface distribution of the coating material was less uniform than expected. However, this may not be considered as an indication of poor effectiveness of a water repellent coating material. In fact, according to the generally accepted criteria of conservation science, a protective coating for natural stones must prevent penetration of condensed water while preserving the open porosity required for water vapour permeation through the treated layer of the stone surface. Thus, while a non-uniform surface distribution of the hydrophobic coating material (e.g., with cracks or lacunas in the coating layer leaving the outer mineral grain exposed) may facilitate water infiltration and absorption by capillarity into the stone, minor differences between the IEP value measured on the coated stone and that of the coating material itself (as measured on a nonporous substrate) may indicate that accessibility to the mineral inner pore surface by the probing electrolyte solution during the electrokinetic measurement is not prevented.

The relative variation $\triangle \mathrm{IEP}$ (Equation (2)) for the six lithotype-treatment combinations reported in Figure 4 does not appear to be correlated in a simple manner with the amount of product applied. In particular, in the case of ANC, a large difference in dry matter from Apuan marble to Balegem stone only corresponded to a negligible increase in $\triangle \mathrm{IEP}$, while a comparable increase in the amount of product from Balegem and Obernkirchen gave rise to a comparatively large increase of $\triangle \mathrm{IEP}$; similarly, in the case of WNC, a minor increase of dry matter from Balegem to Obernkirchen resulted in a large 
increase in $\triangle \mathrm{IEP}$, actually much larger than that recorded from Apuan marble to Balegem in spite of a higher increase in dry matter.

The two products indeed showed markedly different penetration ability, as it is possible to infer from the amount of absorbed dry matter upon treatment (Table 3). WNC has a limited penetration and tends to accumulate on the stone surface, leading to a significant increase in IEP at a comparatively low amount of product applied (Figure 4). By contrast, the higher penetration of ANC results in a tendency to saturate stone porosity, so that a larger amount of product is needed to increase the isoelectric point of the stone surface, as it is especially clear when considering the trend from Apuan marble to Balegem stone (Figure 4).

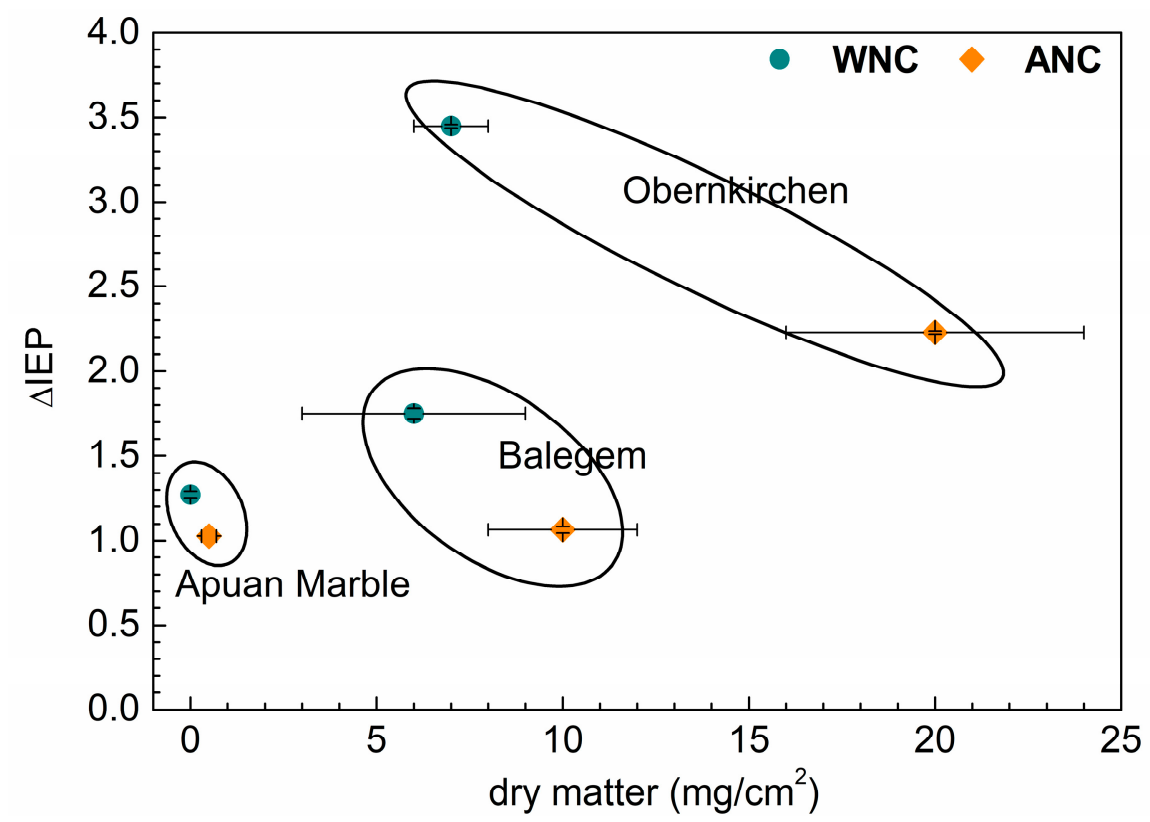

Figure 4. Correlation between dry matter $\left(\mathrm{mg} / \mathrm{cm}^{2}\right)$ and $\triangle \mathrm{IEP}$ (Equation (2)) for lithotypes after treatment with WNC/ANC.

This evidence highlights the complexity of the picture resulting from the contribution of a multiplicity of factors in determining the extent of surface modification, in terms of both the amount of product actually deposited on the surface and the homogeneity of deposition. In particular, among the factors that are most likely to contribute are: (i) the different chemical composition of the alkylalkoxysilane sols, resulting in possibly different reactivity and surface charge of organosilica nanogel particles that are likely to be present along with monomeric and oligomeric silanes; (ii) the different size of nanoparticles dispersed in the two sols (Table 2); (iii) the different porosity, average pore diameter and surface roughness of lithotypes (Table 1); and (iv) their different chemical composition, resulting in different surface charge and specific chemical interaction (covalent or hydrogen bonding) with the sols.

The lower penetration of WNC may be tentatively explained as the result of incipient deposition of nanoparticles onto the outer surface, due to the presence of cationic (IEP $=10.3$; Table 5) and reactive organosilica particles generated by sol-gel partial condensation of the aminated alkylalkoxysilane precursor. It is likely that such particles readily produce a monolayer on the negatively-charged stone surface (more so in the case of Obernkirchen stone, whose IEP is lower than that of the other two stones), which may prevent further absorption and penetration of the product if the stone porosity and pore size distribution are small enough to result in pore clogging, as seems to be the case for WNC on Apuan marble. Indeed, since the $\mathrm{TiO}_{2}$ particle size in $\mathrm{WNC}$ is larger than the average pore size in Apuan marble (Tables 1 and 2), it is reasonable to assume that this component of the nanocomposite formulation does not penetrate into the pores and remains on the stone surface. Further to that, the hydrophobization 
resulting from the incipient modification of the outer stone surface may counteract further absorption and dry matter deposition. Then, additional contributions to the penetration effectiveness may result from the different degree of condensation (see particle size in Table 2) and, albeit to a lower extent, the different viscosity of the matrix-forming alkylalkoxysilane sols.

In order to attempt a quantitative estimation of the extent of surface modification produced by the two coatings, the index of surface modification (ISM) calculated from the isoelectric points of both stones and coatings (Equation (3)) was considered. In accordance with its definition, ISM is a dimensionless parameter that does not depend on the inherent isoelectric points of different coatings, thus making it possible to establish a comparison between them. The validity of this approach was assessed by considering possible correlations of ISM with the reduction of capillary water absorption and surface wettability of treated stones, which are both dependent on the extent of surface hydrophobization. The definition of ISM rests on the assumption that, since films on glass slides make up less heterogeneous surfaces compared to treated stones, their IEP values $\left(\right.$ IEP $\left._{\mathrm{s}}\right)$ may be expected to approximate those of the corresponding products more closely than the values measured on treated stones $\left(\operatorname{IEP}_{t}\right)$. Hence, it was assumed that $\left|\operatorname{IEP}_{\mathrm{s}}-\mathrm{IEP}_{\mathrm{nt}}\right|>\left|\mathrm{IEP}_{\mathrm{t}}-\mathrm{IEP}_{\mathrm{nt}}\right|$ or, equivalently, $0<\mathrm{ISM}<1$, with zero indicating no modification with respect to the untreated stone and one representing the virtual limit condition where the treated stone is homogeneously covered by the coating and behaves in the same way as the product film on glass slides.

The ISM values of ANC are higher than those of WNC (Table 7), yet while on Apuan marble, the difference is relevant, on Balegem and Obernkirchen stones, it is far less so. Moreover, both products display the lowest ISM values on Balegem stone and higher values on Obernkirchen, whereas in the case of Apuan marble, the trend is different: ANC exhibits a value comparable to that seen on Obernkirchen, while the value for WNC is significantly lower. The differences between the two products can be interpreted in the sense that ANC gives rise to a more homogeneous modification of stone surfaces compared to the other product. However, on Balegem and Obernkirchen stones, the difference is rather small and may well fall within the experimental error. The lowest ISM values found on Balegem may be ascribed to the higher nanoscale roughness of this stone (Table 1), which is likely to produce a less effective surface coverage.

Table 7. Index of surface modification (ISM) for the lithotypes treated with WNC or ANC.

\begin{tabular}{ccc}
\hline \multirow{2}{*}{ Stone Type } & \multicolumn{2}{c}{ ISM } \\
\cline { 2 - 3 } & WNC & ANC \\
\hline Apuan marble & $0.71 \pm 0.08$ & $0.91 \pm 0.01$ \\
\hline Balegem & $0.62 \pm 0.09$ & $0.68 \pm 0.07$ \\
\hline Obernkirchen & $0.83 \pm 0.03$ & $0.86 \pm 0.04$ \\
\hline
\end{tabular}

In apparent agreement with the ISM data, the results of water absorption (Table 8) and static contact angle (Table 9) measurements show that ANC is more effective than WNC, and particularly so in reducing water absorption, which is likely to be more suitable than the static contact angle to assess the effectiveness of treatments, indicating the penetration and coverage of the outermost layer of pore walls. The difference between the two products is relevant in the case of Apuan marble and increasingly smaller for Balegem and Obernkirchen stones. Similarly, the difference between the products in the static contact angle with water of treated vs. untreated lithotypes $(\Delta \theta)$ is only evident in the case of Apuan marble, where ANC imparts to the surface a higher hydrophobic character with respect to WNC, while it is totally negligible for the other two stones. 
Table 8. Absorption integrals (in $\mathrm{g} \cdot \mathrm{cm}^{-2} \cdot \mathrm{s}^{0.5}$ ) of untreated (integral $\mathrm{nt}_{\mathrm{nt}}$ ) vs. treated (integral $\mathrm{l}_{\mathrm{t}}$ ) lithotypes and $\mathrm{IC}_{\text {rel }}$ values (= integral $_{\mathrm{t}} /$ integral $_{\mathrm{nt}}$ ).

\begin{tabular}{ccccccc}
\hline \multirow{2}{*}{ Stone Type } & \multicolumn{3}{c}{ WNC } & \multicolumn{3}{c}{ ANC } \\
\cline { 2 - 7 } & Untreated & \multicolumn{2}{c}{ Treated } & Untreated & \multicolumn{2}{c}{ Treated } \\
\cline { 2 - 7 } & Integral $_{\mathbf{n t}}$ & Integral $_{\mathbf{t}}$ & IC $_{\text {rel }}$ & Integral $_{\text {nt }}$ & Integral $_{\mathbf{t}}$ & IC $_{\text {rel }}$ \\
\hline Apuan marble & $1.82 \pm 0.07$ & $1.3 \pm 0.1$ & $0.69 \pm 0.05$ & $1.8 \pm 0.2$ & $0.17 \pm 0.09$ & $0.09 \pm 0.05$ \\
Balegem & $98 \pm 13$ & $15 \pm 4$ & $0.15 \pm 0.04$ & $76 \pm 4$ & $5.2 \pm 0.4$ & $0.068 \pm 0.003$ \\
Obernkirchen & $121 \pm 4$ & $15 \pm 5$ & $0.12 \pm 0.04$ & $124 \pm 4$ & $6 \pm 1$ & $0.05 \pm 0.01$ \\
\hline
\end{tabular}

Table 9. Static contact angles $\left(\theta\right.$, in degrees) of untreated $\left(\theta_{\mathrm{nt}}\right)$ vs. treated $\left(\theta_{\mathrm{t}}\right)$ lithotypes and $\Delta \theta$ values $\left(=\theta_{\mathrm{t}}-\theta_{\mathrm{nt}}\right)$.

\begin{tabular}{ccccccc}
\hline \multirow{2}{*}{ Stone Type } & \multicolumn{3}{c}{ WNC } & \multicolumn{3}{c}{ ANC } \\
\cline { 2 - 7 } & Untreated & \multicolumn{2}{c}{ Treated } & Untreated & \multicolumn{2}{c}{ Treated } \\
\cline { 2 - 7 } & $\theta_{\text {nt }}$ & $\theta_{\mathbf{t}}$ & $\delta \theta$ & $\theta_{\mathbf{n t}}$ & $\theta_{\mathbf{t}}$ & $\Delta \boldsymbol{\theta}$ \\
\hline Apuan marble & $53 \pm 4$ & $129 \pm 13$ & $76 \pm 13$ & $51 \pm 1$ & $141 \pm 2$ & $92 \pm 2$ \\
Balegem & $32 \pm 3$ & $134 \pm 15$ & $101 \pm 16$ & $36 \pm 1$ & $141 \pm 2$ & $106 \pm 3$ \\
Obernkirchen & $21 \pm 3$ & $140 \pm 4$ & $119 \pm 5$ & $17 \pm 7$ & $137 \pm 1$ & $119 \pm 6$ \\
\hline
\end{tabular}

A correlation between ISM values for each coating-stone system and the corresponding $\mathrm{IC}_{\text {rel }}$ values can be made by inspection of Figure 5 . In fact, for each lithotype, the lowest $\mathrm{IC}_{\text {rel }}$ value was obtained for the specimen treated with ANC, the formulation showing the highest ISM value. In particular, the large difference between the products in terms of $\mathrm{IC}_{\text {rel }}$ observed on Apuan marble corresponds to a comparatively large difference in terms of ISM.

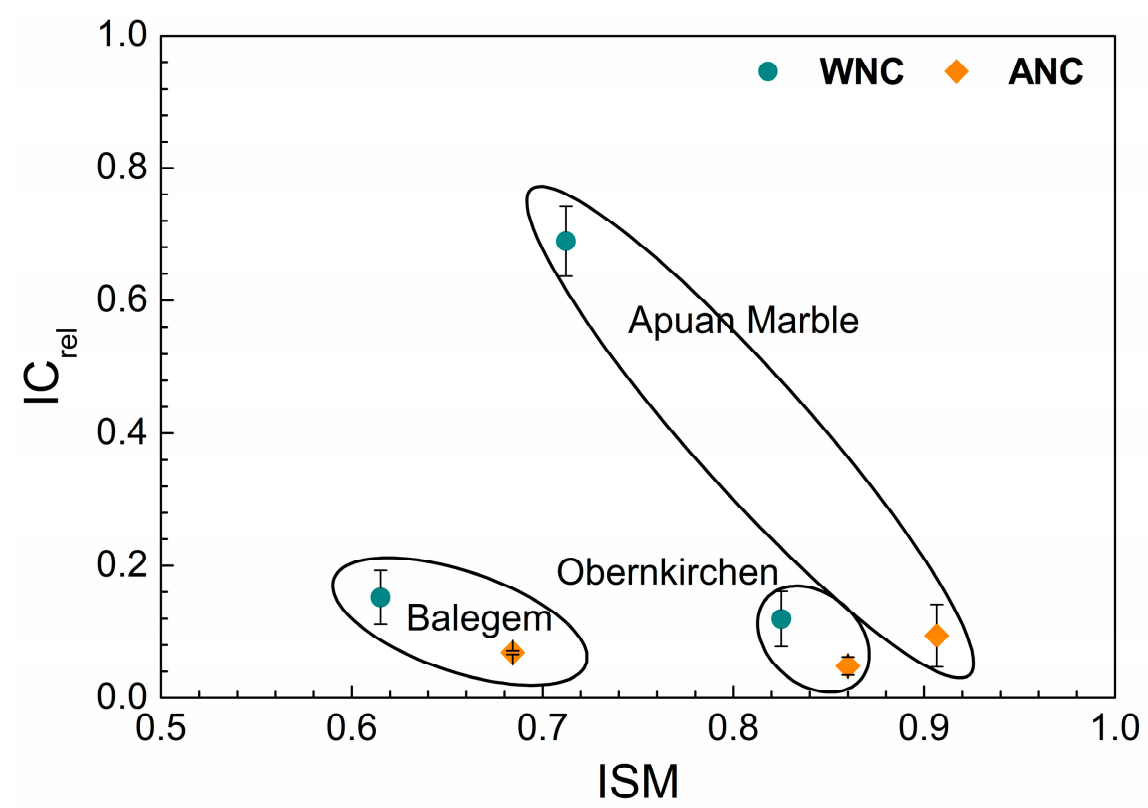

Figure 5. Correlation between the index of surface modification (ISM, Equation (3)) and $\mathrm{IC}_{\text {rel }}$ (see Section 2.4.2) for lithotypes after treatment with WNC/ANC.

Consistent with the observations about $\mathrm{IC}_{\text {rel }}$, the trend of $\Delta \theta$ values for each lithotype also corresponds rather well to that observed for ISM (Figure 6). In particular, for Apuan marble, the large difference in $\Delta \theta$ between WNC and ANC reflects an equally large difference in ISM, while the limited to negligible variation observed for Balegem and Obernkirchen corresponds to a similarly small variation in $\Delta \theta$. Finally, it can be observed that, on Apuan marble, both coatings produced an increase in static 
contact angle that was smaller than that observed on Balegem and Obernkirchen. This deviation may be tentatively ascribed to the much lower porosity of marble, leading to a rather effective coverage of the outer stone surface (and thus high ISM value), but a less effective hydrophobic modification for corresponding low surface energy coating material due to the lower surface roughness of stone and the resulting lower contribution to the measured contact angle by the Cassie-Baxter state $[44,45]$.

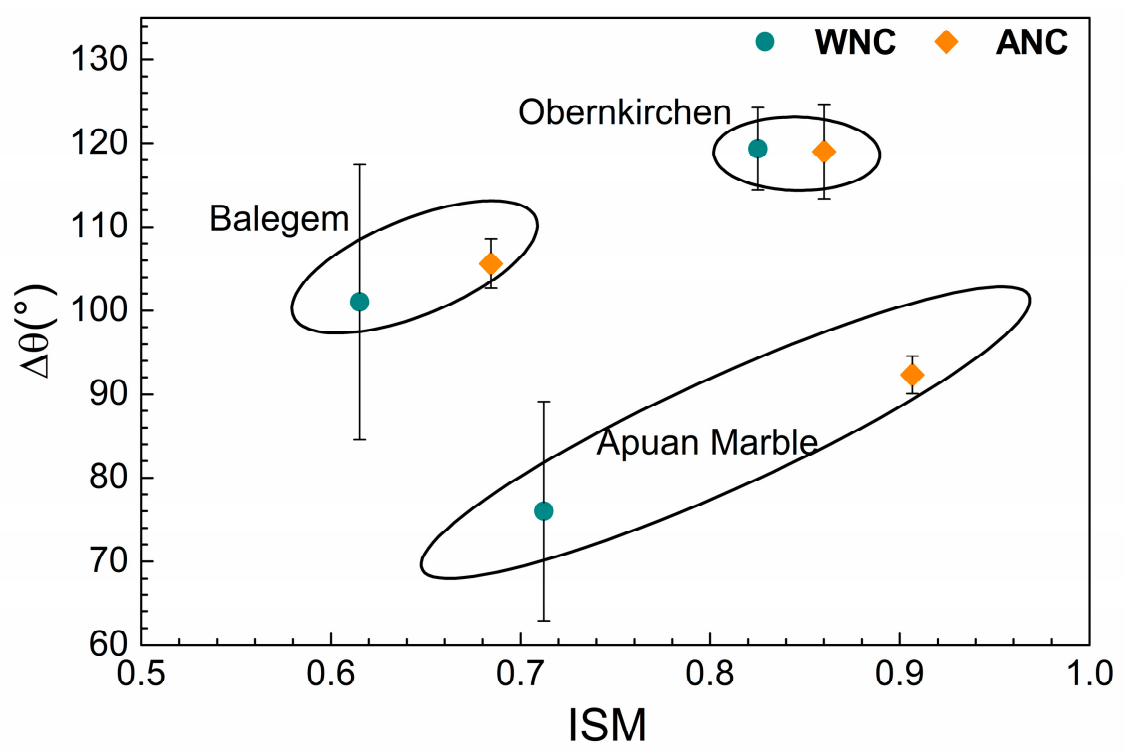

Figure 6. Correlation between the index of surface modification (ISM, Equation (3)) and $\Delta \theta$ (see Section 2.4.3) for lithotypes after treatment with WNC/ANC.

Thus, the empirical ISM parameter, which was anticipated to reflect the extent of surface modification, showed indeed a correlation with the reduction of water absorption and surface wettability of treated stones. In particular, on Balegem and Obernkirchen stones, where the two coatings provided similar results in terms of ISM, similar values of $\mathrm{IC}_{\text {rel }}$ and $\Delta \theta$ were also observed, while their different interactions with water observed on Apuan marble were also accompanied by a greater difference in ISM. In this latter case, ANC was seen to produce a greater reduction in capillary water absorption and a greater increase in static contact angle as compared to the other product. Such a difference reflects, though not exclusively, those seen in the interaction of the products with the stone surface and in their penetration effectiveness, which were discussed earlier with reference to the respective amounts of absorbed dry matter. In particular, the low porosity and low pore diameter of marble, alongside the cationic surface charge (higher IEP with respect to ANC) and larger sized particles in the WNC formulation, result in poorer penetration of this product and are likely responsible for the less homogeneous stone surface modification and less effective hydrophobization achieved.

\section{Conclusions}

Electrokinetic measurements, being sensitive to molecular-level modifications and yet averaging the response over a macroscopically-sized surface area, provide information useful for a more accurate understanding of the different contributions (mineralogy and morphology of stone and nanocomposite product formulation) to the ultimate performance of a coating material. In fact, while they cannot provide spatially-resolved information on the chemical composition of a macroscopic surface, their sensitivity to the extent and nature of the actual surface modifications and the mere fact that the measurements are performed with a probing aqueous electrolyte instead of the high vacuum dry conditions required in most microscopy and spectroscopy measurements offer unique possibilities to investigate the properties of porous materials exposed to the outer environment. This is particularly true for deteriorated stones and for evaluating the effectiveness of treatments expected to protect the 
stone from weathering, the latter being largely determined by the interaction of the porous stone system with condensed water.

In spite of the potential of the technique, several reasons may have prevented until now its use in the field of stone conservation. Among them, the relatively recent availability of user-friendly commercial equipment for streaming potential and streaming current measurements, which have been mostly used by scientists studying separation membranes, materials for biomedical applications and oil well systems. In addition, the morphological complexity and intrinsic mineralogical variability of natural stones (also resulting from chemical transformations upon aging and from the presence of soluble salts in the stone porous network) require a cautious approach to using this technique in order to take into account the many factors influencing the measurements. Only recently, the first examples of streaming potential technique used for measuring the extent of coverage of inorganic nonporous surfaces by nanoparticle adsorption have been reported [46,47]. While the studied systems were simpler than those investigated here, a nontrivial use of theory related to the electrokinetic phenomena was involved.

With the present work:

- electrokinetic analysis based on streaming current measurements was shown to be a sensitive and effective tool to characterize the modification of the surface properties of different natural stones upon application of coating materials;

- a correlation was found between the extent of surface modification (according to the empirical ISM parameter) and the effectiveness of the products as determined by the reduction of water absorption by capillarity and of surface wettability for the six investigated lithotype-nanocomposite coating combinations;

- significant differences were observed between the low porosity Apuan marble and the other two more porous lithotypes, as the former prevents to a large extent penetration of more viscous fluids and possibly of nanoparticles, while the difference between products is, to a good extent, levelled out in the case of the most porous lithotypes as a result of product absorption into the stone matrix.

In summary, the ISM parameter based on streaming current measurements was shown to provide quantitative information on the quality and uniformity of the modification produced by the application of a surface treatment material on a porous substrate when a very thin (not occlusive of the pore structure) coating layer is required. In particular, the effectiveness of the treatment correlates well with the ISM data unless saturation, that is exhaustive coverage of the surface including the pore walls of the outermost layer probed by the streaming current measurement, is achieved.

Further useful and more general applications are foreseen, concerning the characterization of surface treatments based on multicomponent formulations such as micro- or nano-composite coating materials in which the surface properties may be strongly influenced by the preferential segregation of one of the components at the outer coating surface.

Supplementary Materials: The following are available online at http:/ /www.mdpi.com/2076-3417/8/9/1694/s1, Figure S1: SEM images of Apuan marble: (A) untreated; (B) treated with WNC; (C) treated with ANC. Figure S2: SEM images of Balegem stone: (A) untreated; (B) treated with WNC; (C) treated with ANC. Figure S3: SEM images of Obernkirchen stone: (A) untreated; (B) treated with WNC; (C) treated with ANC.

Author Contributions: Conceptualization (L.T. and V.C.); Data curation (M.R.); Funding acquisition (V.C. and L.T.); Investigation (M.R., S.R. and S.B.); Supervision (V.S. and L.T.); Writing, original draft (M.R.); Writing, review and editing (S.R., F.G., L.T. and V.C.).

Funding: This research was funded by the EU Horizon 2020 programme, Grant Number 646178 ("NanoCathedralNanomaterials for conservation of European architectural heritage developed by research on characteristic lithotypes"). S.R. was also funded by the University of Pisa, PRA Project Number 2018_41.

Acknowledgments: The authors wish to thank ChemSpec Srl (Italy) and Colorobbia Consulting Srl (Italy) for supplying the nanomaterials, Mag. Matea Ban from the Vienna University Technology for the mercury intrusion porosimetry measurements, Thomas Luxbacher from Anton Paar GmbH (Austria) for initial scientific advice and 
Marco Lezzerini from the University of Pisa for performing X-ray diffraction measurements and for providing the calcite monocrystal sample.

Conflicts of Interest: The authors declare no conflict of interest.

\section{References}

1. Snethlage, R. Stone conservation. In Stone in Architecture: Properties, Durability, 5th ed.; Siegesmund, S., Snethlage, R., Eds.; Springer: Berlin/Heidelberg, Germany, 2014; pp. 415-550. ISBN 978-3-662-49573-5.

2. Della Volpe, C.; Penati, A.; Peruzzi, R.; Siboni, S.; Toniolo, L.; Colombo, C. Combined effect of roughness and heterogeneity on contact angles: The case of polymer coating for stone protection. J. Adhes. Sci. Technol. 2000, 14, 273-299. [CrossRef]

3. De Ferri, L.; Lottici, P.P.; Lorenzi, A.; Montenero, A.; Salvioli-Mariani, E. Study of silica nanoparticlesPolysiloxane hydrophobic treatments for stone-based monument protection. J. Cult. Herit. 2011, 12, $356-363$. [CrossRef]

4. Fermo, P.; Cappelletti, G.; Cozzi, N.; Padeletti, G.; Kaciulis, S.; Brucale, M.; Merlini, M. Hydrophobizing coatings for cultural heritage. A detailed study of resin/stone surface interaction. Appl. Phys. A 2014, 116, 341-348. [CrossRef]

5. Crupi, V.; Fazio, B.; Gessini, A.; Kis, Z.; La Russa, M.F.; Majolino, D.; Masciovecchio, C.; Ricca, M.; Rossi, B.; Ruffolo, S.A.; et al. $\mathrm{TiO}_{2}-\mathrm{SiO}_{2}-\mathrm{PDMS}$ nanocomposite coating with self-cleaning effect for stone material: Finding the optimal amount of $\mathrm{TiO}_{2}$. Constr. Build. Mater. 2018, 166, 464-471. [CrossRef]

6. Lettieri, M.; Masieri, M. Surface characterization and effectiveness evaluation of anti-graffiti coatings on highly porous stone materials. Appl. Surf. Sci. 2014, 288, 466-477. [CrossRef]

7. La Russa, M.F.; Rovella, N.; De Buergo, M.A.; Belfiore, C.M.; Pezzino, A.; Crisci, G.M.; Ruffolo, S.A. Nano- $\mathrm{TiO}_{2}$ coatings for cultural heritage protection: The role of the binder on hydrophobic and self-cleaning efficacy. Prog. Org. Coat. 2016, 91, 1-8. [CrossRef]

8. Xiong, Q.; Baychev, T.G.; Jivkov, A.P. Review of pore network modelling of porous media: Experimental characterisations, network constructions and applications to reactive transport. J. Contam. Hydrol. 2016, 192, 101-117. [CrossRef] [PubMed]

9. Doehne, E.; Price, C.A. Stone Conservation: An Overview of Current Research, 2nd ed.; The Getty Conservation Institute: Los Angeles, CA, USA, 2010; ISBN 978-1-60606-046-9.

10. Andreotti, S.; Franzoni, E.; Fabbri, P. Poly(hydroxyalkanoate)s-based hydrophobic coatings for the protection of stone in cultural heritage. Materials 2018, 11, 165. [CrossRef] [PubMed]

11. Luxbacher, T. The Zeta Guide: Principles of the Streaming Potential Technique; Anton Paar GmbH: Graz, Austria, 2014.

12. Von Smoluchowski, M. Contribution à la théorie de l'endosmose électrique et de quelques phénomènes corrélatifs. Bull. Acad. Sci. Cracovie. 1903, 8, 182-200.

13. Ristić, T.; Hribernik, S.; Fras-Zemljič, L. Electrokinetic properties of fibres functionalised by chitosan and chitosan nanoparticles. Cellulose 2015, 22, 3811-3823. [CrossRef]

14. Ripoll, L.; Bordes, C.; Marote, P.; Etheve, S.; Elaissari, A.; Fessi, H. Electrokinetic properties of bare or nanoparticle-functionalized textile fabrics. Colloids Surf. A 2012, 397, 24-32. [CrossRef]

15. Déon, S.; Fievet, P.; Doubad, C.O. Tangential streaming potential/current measurements for the characterization of composite membranes. J. Membr. Sci. 2012, 413-421. [CrossRef]

16. Wang, Y.; Guo, L.; Ren, L.; Yin, S.; Ge, J.; Gao, Q.; Luxbacher, T.; Luo, S. A study on the performance of hyaluronic acid immobilized chitosan film. Biomed. Mater. 2009, 4, 035009. [CrossRef] [PubMed]

17. Heberling, F.; Trainor, T.P.; Lützenkirchen, J.; Eng, P.; Denecke, M.A.; Bosbach, D. Structure and reactivity of the calcite-water interface. J. Colloid Interface Sci. 2011, 354, 843-857. [CrossRef] [PubMed]

18. Kershner, R.J.; Bullard, J.W.; Cima, M.J. Zeta potential orientation dependence of sapphire substrates. Langmuir 2004, 20, 4101-4108. [CrossRef] [PubMed]

19. Laumann, S.; Micić, V.; Lowry, G.V.; Hofmann, T. Carbonate minerals in porous media decrease mobility of polyacrylic acid modified zero-valent iron nanoparticles used for groundwater remediation. Environ. Poll. 2013, 179, 53-60. [CrossRef] [PubMed] 
20. Adamczyk, Z.; Sadlej, K.; Wajnryb, E.; Nattich, M.; Ekiel-Jezewska, M.L.; Bławzdziewicz, J. Streaming potential studies of colloid, polyelectrolyte and protein deposition. Adv. Colloid Interface Sci. 2010, 153, 1-29. [CrossRef] [PubMed]

21. Szymczyk, A.; Dirir, Y.I.; Picot, M.; Nicolas, I.; Barrière, F. Advanced electrokinetic characterization of composite porous membranes. J. Membr. Sci. 2013, 429, 44-51. [CrossRef]

22. Cerepi, A.; Loisy, C.; Toullec, R.; Burlot, R.; Galaup, S.; Schmutz, M. Electrical behaviour of saturated and unsaturated geological carbonate porous systems. Stud. Surf. Sci. Catal. 2006, 160, 713-719.

23. Vdović, N.; Bišćan, J. Electrokinetics of natural and synthetic calcite suspensions. Colloids Surf. A 1998, 137, 7-14. [CrossRef]

24. Kanellopoulou, D.G.; Koutsoukos, P.G. The calcitic marble/water interface: Kinetics of dissolution and inhibition with potential implications in stone conservation. Langmuir 2003, 19, 5691-5699. [CrossRef]

25. Zhao, Z.; Wang, G. Surface electrical property and adsorption performance of Maifan stone. J. Nat. Sci. Heilongjiang Univ. 2007, 24, 357-360.

26. Falchi, L.; Balliana, E.; Izzo, F.C.; Agostinetto, L.; Zendri, E. Distribution of nanosilica dispersions in Lecce stone. Sciences at Cà Foscari 2013, 1, 39-46.

27. Lezzerini, M.; Marroni, M.; Raneri, S.; Tamayo, S.; Narbona, B.; Fernández, B.; Weber, J.; Ghaffari, E.; Ban, M.; Rohatsch, A. Part I: Natural stone test methods. In D1.5-Mapping of Stones and Their Decay; Nano-Cathedral Project Grant Agreement No. 646178-Confidential Deliverable; Nano-Cathedral: Pisa, Italy, 2017; pp. 8-16.

28. Giesche, H. Mercury porosimetry: A general (practical) overview. Part. Part. Syst. Charact. 2006, $23,9-19$. [CrossRef]

29. Roveri, M.; Gherardi, F.; Goidanich, S.; Niccolai, L.; Dami, V.; Toniolo, L. Use of Nanomaterials for the Protection of Historic Stone Architecture: Laboratory Methods for the Evaluation and Investigation of Photocatalytic Activity. In Proceedings of the 4th WTA International PhD Symposium, Delft, The Netherlands, 13-16 September 2017; Quist, W.J., Granneman, S.J.C., van Hees, R.P.J., Eds.; TU Delft: Delft, The Netherlands, 2017.

30. Gherardi, F.; Roveri, M.; Goidanich, S.; Toniolo, L. Photocatalytic nanocomposites for the protection of european architectural heritage. Materials 2018, 11, 11010065. [CrossRef]

31. EN 16581:2014. Surface protection for porous inorganic materials: Laboratory test methods for the evaluation of the performance of water repellent products. In Conservation of Cultural Heritage; European Committee for Standardization: Brussels, Belgium, 2014.

32. Yaroshchuk, A.; Luxbacher, T. Interpretation of electrokinetic measurements with porous films: Role of electric conductance and streaming current within porous structure. Langmuir 2010, 26, 10882-10889. [CrossRef] [PubMed]

33. EN 15801:2009. Test methods-Determination of water absorption by capillarity. In Conservation of Cultural Property; European Committee for Standardization: Brussels, Belgium, 2009.

34. Peruzzi, R.; Poli, T.; Toniolo, L. The experimental test for the evaluation of protective treatments: A critical survey of the "capillary absorption index". J. Cult. Herit. 2003, 4, 251-254. [CrossRef]

35. EN 15802:2009. Test methods-Determination of static contact angle. In Conservation of Cultural Property; European Committee for Standardization: Brussels, Belgium, 2009.

36. Schnitzer, C.; Ripperger, S. Influence of surface roughness on streaming potential method. Chem. Eng. Technol. 2008, 31, 1696-1700. [CrossRef]

37. Kosmulski, M. Compilation of PZC and IEP of sparingly soluble metal oxides and hydroxides from literature. Adv. Colloid Interface Sci. 2009, 152, 14-25. [CrossRef] [PubMed]

38. Alvarez-Silva, M.; Uribe-Salas, A.; Mirnezami, M.; Finch, J.A. The point of zero charge of phyllosilicate minerals using the Mular-Roberts titration technique. Miner. Eng. 2010, 23, 383-389. [CrossRef]

39. Vdović, N. Electrokinetic behaviour of calcite-The relation with other calcite properties. Chem. Geol. 2001, 177, 241-248. [CrossRef]

40. Hayes, R.A.; Böhmer, M.R.; Fokkink, L.G.J. Study of silica nanoparticle adsorption using optical reflectometry and streaming potential techniques. Langmuir 1999, 15, 2865-2870. [CrossRef]

41. Dussaud, A.D.; Breen, P.C.; Koczo, K. Characterization of the deposition of silicone copolymers on keratin fibers by streaming potential measurements. Colloids Surf. A 2013, 434, 102-109. [CrossRef]

42. Lee, C.H.; Park, S.H.; Chung, W.; Kim, J.Y.; Kim, S.H. Preparation and characterization of surface modified silica nanoparticles with organo-silane compounds. Colloids Surf. A 2011, 384, 318-322. [CrossRef] 
43. Kosmulski, M. The significance of the difference in the point of zero charge between rutile and anatase. Adv. Colloid Interface Sci. 2002, 99, 255-264. [CrossRef]

44. Cassie, A.B.D.; Baxter, S. Wettability of porous surfaces. Trans. Faraday Soc. 1944, 40, 546-551. [CrossRef]

45. Brugnara, M.; Degasperi, E.; Volpe, C.D.; Maniglio, D.; Penati, A.; Siboni, S.; Toniolo, L.; Poli, T.; Invernizzi, S.; Castelvetro, V. The application of the contact angle in monument protection: New materials and methods. Colloids Surf. A 2004, 241, 299-312. [CrossRef]

46. Morga, M.; Adamczyk, Z.; Kosior, D. Silica monolayer formation and stability determined by in situ streaming potential measurements. Electrochim. Acta 2016, 206, 409-418. [CrossRef]

47. Schabikowski, M.; Zalewska, M.; Kata, D.; Graule, T. The effect of CuO coatings on the electrokinetic properties of stonewool fibres determined by streaming potential measurements. Ceram. Int. 2016, 42, 13944-13951. [CrossRef]

(C) 2018 by the authors. Licensee MDPI, Basel, Switzerland. This article is an open access article distributed under the terms and conditions of the Creative Commons Attribution (CC BY) license (http://creativecommons.org/licenses/by/4.0/). 